\title{
Hostile to Hierarchy? Individuality, Equality and Moral Boundaries in Dutch Class Talk
}

\section{Gwen van Eijk}

Leiden University, The Netherlands

\begin{abstract}
Cultural class analysts point to the hidden and morally loaded nature of class in explaining people's ambivalence towards class and their position in the class hierarchy. This article examines the way in which Dutch respondents draw on cultural repertoires about equality and individuality to deny or flatten class hierarchy and individualize class differences. The equality ideal reverberates in the uncoupling of socio-economic differences from moral boundaries. The study shows that highereducated respondents in particular construct a class hierarchy based on education. Interpreting cultural boundaries in terms of education is conducive to moral evaluations and hierarchalization. Drawing cultural boundaries in terms of taste is not conducive to hierarchalization. The study shows that notions of individuality, through individualizing class positions, work to both deny and conceal class differences in relation to cultural resources. In addition, the study shows the relevance of cultural class analysis for Dutch sociology and society.
\end{abstract}

\section{Keywords}

class, cultural repertoires, equality, individuality, moral boundaries

\section{Introduction}

Class is a difficult subject, for lay people as well as for sociologists. Cultural class analysts have pointed to the hidden and morally loaded nature of class, which would result in denial, ambivalence, strategies to displace class as something that only exists 'out there' and defensiveness as resistance to moral devaluation (e.g. Reay, 1997; Savage, 2000; Savage et al., 2001; Sayer, 2005). This makes it difficult for people to recognize and talk about class and for sociologists to understand how class matters in social and

\section{Corresponding author:}

Gwen van Eijk, Institute for Criminal Law and Criminology, Leiden Law School, Leiden University, P.O. Box 9520, 2300 RA, Leiden, The Netherlands.

Email: g.van.eijk@law.leidenuniv.nl 
cultural life: Does denial mean that class is insignificant, or is it a strategy to distance oneself from the unjust working of class? In analyzing ambivalence in class talk, two related but different interpretations have been offered. The first interpretation holds that the working of class is difficult to articulate because it often operates in a hidden way (Bottero, 2004; Bourdieu, 1984; Savage, 2000). In social and cultural life, class is 'deeply embedded in everyday interactions, in institutional processes, in struggles over identity, validity, self-worth and integrity even when it is not acknowledged' (Reay, 2005: 924). Because it is embedded in social relations, and people's social position and culture are intertwined in everyday social practices, 'hierarchical practices emerge as "second nature", unremarkable and ordinary' (Bottero, 2004: 995). In fact, in Bourdieu's view, the habitus and acquired dispositions and tastes are most effective in the process of distinction when they function 'below the level of consciousness and language', providing people 'a sense of one's place' (1984: 466). What is more, those whose disposition and taste are rejected by the dominating class adjust their expectations and adopt the same view, so that misrecognition is hidden even for the dominated class (1984: 466). A second strand of interpretations of ambivalence emphasizes the morally problematic nature of class (Sayer, 2005). Deeply felt emotions of embarrassment, anger and shame make it difficult to talk about class (Reay, 1997). Class conflicts with our idea that everybody is, or should be, of equal moral worth. Thinking and talking about class is not just about differences: it is about superiority and inferiority related to an unjust (because to some extent arbitrary) inequality in economic, cultural and political resources. What troubles people is not so much that there are differences, but that these imply a hierarchy of worthiness. This would explain responses of defensiveness and denial: people want 'both to acknowledge its unfairness as a social structure and to exempt themselves from complicity in it' (Sayer, 2005: 202). Hence reluctance to talk about class should not be interpreted as a denial of the existence of class (2005: 202).

In this article I want to draw attention to particular 'cultural repertoires' (Lamont, 2000) that help either to deny class hierarchy or to conceal the classed nature of perceptions of a moral hierarchy. Starting point of the argument is that the taboo on class results not from an inherent difficulty but from prevailing ideas that make class hierarchy problematic. Indeed, class hierarchy was not always hidden and did not always invoke anger or embarrassment. In the UK, until the late 19th century, societal hierarchy was seen as 'natural' and the best guide to individual identities (Cannadine, 1998; Day, 2001). People had no trouble with looking down on those 'lower' in the social order and, reversely, accepting the moral authority of those in 'higher' socio-economic or power positions. Certain radical transformations of western societies provided the circumstances and means to challenge the moral hierarchy (Day, 2001). One of such changes involves the emancipation of previously powerless categories such as workers, women and ethnic or racial minorities, which resulted in the democratization of civil and political rights and the levelling of power differences. In this process, class differences and expressions of superiority in particular became taboo and norms of informality and mutual respect in interactions helped conceal hierarchical relations (Wouters, 2011). As emancipation and the accompanying social mobility permeated more domains in society, resistance to social hierarchies and authority, and expressions of superiority grew stronger. We can thus argue that the emancipation process supported and reinforced egalitarian thinking, 
which, clearly, conflicts with notions of class, as class implies an uneven distribution of recognition.

Another well-known transformation that conflicts with class hierarchy is produced by the process of individualization. The declining significance of institutions such as family, church, neighbourhood and class for defining people's identity and determining the life course, implies increasing individual freedom as relationships became less interdependent and traditions less determining for actions and choices. Although the extent to which individualization has eroded class remains a point of debate (Atkinson, 2007; Savage, 2000), it is safe to say that it has changed the way in which people view themselves and their place in society. Individualization as a structural transformation compels people 'to make themselves the center of their own planning and conduct of life' (Beck, 1992: 88); the emerging notion of individuality emphasizes individual autonomy, uniqueness and personal happiness. Not only do people experience more freedom of choice, they also have come to expect it and expect others to make independent choices. The dominant view that individuals now need to make choices based on their tastes and (chosen) lifestyles in order to lead fulfilling lives helps to hide the ways in which lifestyles and relationships are structured along lines of milieu and upbringing, educational level, occupation and societal status (Bennett et al., 2009; Bourdieu, 1984). The 'socially innocent language of likes and dislikes' (Bourdieu, 1984: 241) masks the classed matching of lifestyles and offers people a cultural repertoire that helps them to deny or ignore the working of class. This is also reflected in people's sense that they choose relationships, thus rejecting the reality that the formation of relationships is fundamentally shaped by class-based similarities in economic and cultural capital. This is not to deny that transformations such as emancipation and individualization altered class relations, but to take note of the ways in which such transformations are also important for offering cultural repertoires that in themselves help to hide class and help people to deny or ignore the classed nature of moral hierarchies.

The main focus of this article is the notion of individuality rather than egalitarianism. We will see that the notions of both equal worth and individuality reverberate in lay narratives on (the insignificance of) class, offering people tools to deny or invert class hierarchy. With regard to egalitarianism, the interviews with Dutch respondents show findings that compare with Savage et al.'s (2001) observations on the 'omnivoric refrain' and 'ordinariness' and Sayer's (2005) observation of discomfort related to denying complicity. However, with respect to notions of individuality, the Dutch interviews show an alternative reading of how the 'individualistic ethic' (Savage et al., 2001) works through in lay understandings of class and constructions of class hierarchy. Before explaining this in more detail, I discuss the taboo on class in the Netherlands.

\section{The Dutch Taboo on Class}

'Class' is a word that is rarely used by Dutch people, neither in socio-political debates nor in everyday language, illustrating the common-sense opinion that class no longer matters in Dutch society. However, until the mid-1960s, class was one of the most important social divisions, next to religion (Goudsblom, 1967; Lijphart, 1975; Wouters, 1990). From the late 19th century until the late 1960s, Dutch society was divided in various 
'pillars', organized mainly around denominational lines. Across the pillars, society was socio-economically divided in a higher-middle, lower-middle and working class. Class differences were notable in terms of income but also subjectively experienced: people had a sense of their own and others' class position. For instance, a 1948 UNESCO study on perceived class divisions shows that the Netherlands scores second on the class cleavage index (after Germany; Britain scores fourth), which indicates that class differences are relatively visible and strong (Lijphart, 1975). However, openly discriminating based on class was usually condemned and class in general was an unpopular subject (Goudsblom, 1967). Compared to other West-European countries, resistance to the hierarchical order came late in the Netherlands: class differences became a taboo only after the 1950s (De Swaan, 1997; Wouters, 1990). Notwithstanding, resistance was intense: in the 1960s and 1970s, it seemed Dutch society was 'catching up' with the rest of the western world in terms of emancipation and informalization (Wouters, 1990). This is key for understanding the strong conviction that class has disappeared.

In addition, today, the 'culturalization' of social problems (Duyvendak et al., 2009) has overshadowed class divisions in socio-political debates. Politicians, policy makers and the media are preoccupied with ethnic or 'cultural' differences - and, more recently, 'religious' differences as concerns about Islam increase. Politicians and policy makers do talk about socio-economic status, income, education, social mobility, deprivation, distinguishing the lower and higher educated, low and high income groups, the underprivileged and the privileged. Yet, class hierarchy is invoked only implicitly (cf. Lawler, 2005), particularly in policies on education, culture and integration of ethnic minority groups. Higher education, cultural participation and self-actualization are valued more and those who can 'grow' should choose to do so. However, a Dutch government advice body recently concluded, against the current, that 'we tend towards a class society' (Zeldenrijk, 2010: 6). New divisions along lines of education are manifest not only in education and career opportunities but also through housing and political participation (RMO, 2011). In addition, within the domain of education, some forms, notably vocational training, are underappreciated in society. According to the Minister of Education (2012), the report is a 'serious signal' which calls for 'more insight into possible new social divisions'.

As of now, Dutch sociology offers little insight into class as a social construct that gives meaning to similarity and difference and which reflects and (re)produces social divisions. In fact, a 2006 report of the Royal Netherlands Academy of Arts and Sciences on the future of Dutch sociology discards class as key sociological concept, arguing that the significance of class has been impaired by processes of globalization and individualization (KNAW, 2006). The committee chair (Engbersen, 2005) questions the extent to which 'class' meets C. Wright Mills' criteria of 'actual experience' (connecting biography and history). Further, he contends that 'class' can hardly be defined as a 'process concept' (in the Elian sense) and is therefore prone to reification (2005).

This diagnosis is problematic (see also Weenink, 2005). First of all, it is hard to see why class differences would not be 'actually' experienced in everyday lives. We are constantly confronted with differences in education, income, power, opportunities and taste, perhaps not through our closest relationships but then surely through work and leisure (e.g. successful professionals are served and supported by cleaners, caterers 
and carers; Sassen, 2001) and, above all, the media. In our consumer culture the importance of consumption for shaping our identity is constantly emphasized and many of us measure ourselves and others against standards of possessions, lifestyle choices and taste. In an age that favours individual achievement, we find reasons to be obsessed with how well others do and to look down on those who 'lag behind'. Current neoliberal politics constantly reminds us of the importance of socio-economic achievement, for our own 'health' as well as for a 'healthy' economy. Furthermore, globalization and individualization - defined by Engbersen as 'actually experienced' processes - do not rule out the importance of class, although they surely alter its role (Savage, 2000; Savage et al., 2005). Finally, there may indeed be a danger of reification for more traditional conceptualizations of class, but cultural class analyses (Bennett et al., 2009; Bourdieu, 1984; Lamont, 2000; Savage, 2000) explicitly attempt to avoid reification, focusing on the changing nature of class and class relations in contemporary society. They also emphasize that class is not an essence but a relational concept that is shaped in, and in turn shapes, social relations. Class in this understanding is not only a matter of occupation, income and education, but something that is constituted through symbolic and cultural practices (Lawler, 2005); an 'everyday process' which is 'powerfully internalised and continually played out in interaction with others across social fields' (Reay, 1997: 226).

This analysis seems well applicable to Dutch society, as the few studies that follow a cultural class analysis approach demonstrate how class permeates constructions of similarity and differences. For instance, Kuipers (2006) shows that people's ideas about good and bad humour are imbued with references to class: "jokes are associated with the "lower classes"; the telling of jokes of this sort is seen as "bad taste" and "of a lower level"' (2006: 49). In choosing a school for one's child, higher-educated parents in particular are guided by class differences (De Regt and Weenink, 2003; Zeldenrijk, 2010). Parents are, for instance, afraid that the wrong school will negatively affect not so much their child's future socio-economic status but his or her 'development' (De Regt and Weenink, 2003). Self-actualization is thus more important than money. All these studies show that people feel uncomfortable with talking about class and they find it hard to pinpoint class differences; the parents in Zeldenrijk's (2010) study 'just feel it', but nonetheless they do see class differences.

Class is a 'latent identity' De Regt and Weenink (2003) conclude: people often talk about class only indirectly, but certain situations may activate class identity; for example, encounters with rich people, experiences with low-level education or the context of an interview on class. But class is a latent identity not only because other identities have come to fulfill a more significant role in constructing difference and similarity. Class identity is also latent in everyday social and cultural life because it is a very well concealed identity. After describing the data, the article shows how notions of equality and individuality compel Dutch people to deny and ignore the classed nature of practices and preferences.

\section{Data}

This article draws on in-depth interviews with 27 people living in two neighbourhoods in Rotterdam. For the purpose of the larger research project I wanted to interview people 
with different socio-economic positions and thus the respondents range from low educated non-working people to highly educated (self-)employed professionals (see for full details, Van Eijk, 2010). Following a survey, the interviews were carried out in 2009 and designed to probe respondents about personal relationships. As part of the interview I asked respondents about perceived similarity and differences between themselves and their network members. I started out with open questions ('In what respect are you similar/different?') in order to see whether respondents would talk about class spontaneously. While aspects that we could see as 'class' did come up, 'class' was only explicitly mentioned by two respondents.

The final part of the interview was explicitly about class and this part is analyzed for this article. I started with a standard question on self-classification: 'Sometimes people divide society into classes, for example working class, middle class and upper class. If you were asked to place yourself in such a scheme, where would you place yourself?' Of the 27 people that I interviewed, nine did not stick to one category: three self-classified as 'lower class' with the qualification 'temporary' and six offered a position in between, or a combination of, 'middle class' and 'upper class'. Of those who did choose one category, 14 said 'middle class', two chose 'upper class' and another two refused to selfclassify. I then asked people to explain their choice for a certain class, after which I asked them to classify their network members as belonging to the same or a different class. I particularly probed about network members whom respondents classified as belonging to a different class.

It can be argued that respondents talked about class only because I asked them to. That is true, in a sense, in that most of them had not used the word 'class' up to the point that I explicitly asked them about it. However, I did not, in any case not in the first instance, direct their understanding of what 'class' means. Whenever respondents asked what I meant, I would make clear that I wanted to leave it open to them. In a few cases respondents asked for clarification and then I would offer various meanings ('income, education, milieu, lifestyle'). Furthermore, I sometimes probed about alternative meanings (e.g. by saying 'You can also think about class in a different way ...'). Thus, while I did put the word 'class' in their mouths, respondents themselves gave meaning to the concept.

\section{Socio-economic Boundaries: Equality and the Middle Position}

The interviews show that people draw class divisions based on multiple types of boundaries, which corresponds with Lamont's (1992) distinction between socio-economic, cultural and moral boundaries. The following three sections take each of the three boundaries as a starting point for investigating the ways in which they matter for perceptions of class differences versus class hierarchy and the ways in which respondents draw on particular cultural repertoires to flatten class hierarchy or to individualize class position.

People draw socio-economic boundaries on the basis of people's social position as indicated by material success, professional prestige, power and visibility in prestigious social circles (Lamont, 1992). Nearly all respondents pointed to socio-economic differences - income level, job position, property, self-reliance - in order to locate themselves in the class hierarchy. As in other studies, those respondents who say they 
are 'middle class' differ greatly. Among them are five people with only primary or secondary education, two of whom are low educated and unemployed. Others have a higher vocational or academic degree and work as a teacher, nurse, manager or GP. One reason for choosing the middle position is that respondents compare themselves to others 'above' and 'below' them, including people they know about through work or the media (cf. Pahl et al., 2007). It is thus not because they socialize mainly with similar people, thinking that they are 'normal and unexceptional' (Bottero, 2004; Evans et al., 1992; Pahl et al., 2007), but because they compare themselves to others who are doing better or worse than them, finding themselves 'in the middle' - having a 'normal' or 'average' position (cf. Savage et al., 2001). For example, being a social worker, Els (39, higher vocational training) sees her position as 'higher than my average client'. She also had information about people 'above' her through reading about the life of a professor whom she thinks 'must be really smart'. She thus contrasts her position with people who are of higher and lower socio-economic status and locates herself in a quite average position. Having worked in a dry cleaner's, Jannie (59, unemployed, low vocational training) would recognize upper-class people by their clothes, shoes and attitude. She further refers to the drama series Gooische Vrouwen [Women of the Gooi] about women who live in Het Gooi, known in the Netherlands as the area where the rich and famous live (it is located near the Dutch TV studios) for knowledge about people outside her own circle - and of a higher class.

While some respondents talked quite easily about socio-economic differences and corresponding class positions, others made it clear that they were uncomfortable with ranking people. They connected a socio-economic hierarchy with superiority and inferiority in terms of personal worthiness and thus felt compelled to apologize, deny or resist. This could be interpreted as a strategy to avoid complicity with or resist domination of the class hierarchy (Sayer, 2005). For example, those who self-classified as 'lower class' said this was only temporary because of unemployment due to certain reasons. With a job and income, they would belong to the middle class. Maureen, who was at the time of the interview unemployed, self-classified as middle class, arguing that: 'Just because you're at home that doesn't mean you're low. Because someone like me, I'm not gonna say I'm low' (38, formerly cleaner, primary education). Some respondents explicitly said that they did not like to talk about who is 'more' or 'less', thus implying that they understood class not as a neutral classification but as a ranking of worthiness. Classifying oneself and others became morally loaded. One of the two respondents who refused to self-classify altogether said:

No, I don't sort myself into classes, I can adjust to anyone. Whether it's upper class [...] I don't feel that difference really. But how they talk, you would notice that of course. But I myself don't classify, I don't. [...] Whether you're the Queen or a country bumpkin that doesn't matter, you should acknowledge everyone's own worth, and if you've respect for me than I'll return respect, but if you don't, then I think well who are you to, should I feel inferior to you? (Riet, 63 , retired shop assistant, secondary education)

Umaima, of Pakistani origin, resisted the inferiority of not only her socio-economic status but also of her ethnic origin, thus rejecting the socio-politically dominant view that non-western ethnicity is linked to deprivation and problems: 
Yeah I do have an idea about that [what class is], but I'm not that kind of person, I think everybody's the same. I'm not gonna say, like he's less or I'm more or she's more, no, we're all the same, no matter from which country we are, whether we're Dutch or Pakistani, that's no difference to me. (40, unemployed, formerly administrative worker, lower vocational training)

When I suggested that class does not have to be about being more or less, but that it can be about differences, she responded by saying that she does see differences in terms of work and housing and then classified herself as both lower (in terms of work) and middle class (in terms of housing).

The objection to a socio-economic hierarchy based on the idea that 'everybody is of equal worth' echoes the strong egalitarian strain in Dutch culture (e.g. Kuipers, 2006; Van den Brink, 2004; Van Elteren, 1998). However, the growing belief in egalitarianism that accompanied the wave of emancipation in the 1960s and 1970s did not liberate people from feelings and expressions of superiority and inferiority. Rather, it implied that such feelings and expressions were increasingly curbed and forbidden (De Swaan, 1997; Wouters, 2011). Hence we can understand respondents' apologies and denials not as a sign of absent class differences but as the result of a taboo on class differences. That respondents are particularly uncomfortable with talking about those located 'below' them, supports this interpretation. Daniel (44, IT manager, higher vocational training) thus felt the need to apologize for expressing superiority. He thought it was 'presumptuous' and 'not easy' to say that in terms of education he belonged to the upper class. $\mathrm{He}$ found it 'rotten' to classify others in terms of class because 'you degrade someone, instead of grading'. Also, respondents who self-classified as middle class stressed that they did not feel 'more' than those below, Dominique for example:

The classification is quickly made for salaries, minimum income, normal income, top [income]. But it's not that I feel elevated above others or something. That's nonsense. But I think I'm just average. (39, contract settler, high vocational training)

Respondents had less difficulty talking about those 'above' them. Anita had no problems placing herself and several of her relations in the middle class and her sister in the upper class, based on job positions, but when I asked her whether she knew anyone whom she would classify as being lower class, she resisted making that classification:

Well, I feel, I don't like to classify people, I feel anyway that everybody should live like he pleases and of course I know people who live on social security and that's indeed difficult to make ends meet so then I think, well [compared] to them I'm doing well, so yes, but therefore they're not a lesser human being of course. (59, management assistant, secondary education)

Here is another example:

Gwen: Do you also know people in the lower class?

Bernadette: My sister-in-law, if I have to call that class

G: $\quad$ Because she ... the one who works in home care? 
Yes. Because she's falling into poverty, I find that sad, because she did work, but because of her divorce ... (52, middle manager, higher vocational training).

Bernadette does not want to 'call that class' when she talks about someone who lives in poverty, while just before she self-classified as middle class and distinguished herself from the upper class because she was not born in Het Gooi and her family always had worked hard to build up a life, without making any qualifications. Respondents thus seem careful not to judge those who are at the 'bottom' of the hierarchy, while they have no problem making statements about those supposedly at the 'top'. For some, this was also a personal matter. Jannie distanced herself from both the upper and lower classes, stating that wealthy people are 'haughty' and 'posh', but was careful not to judge the lower class because, being on disability benefits herself, 'who knows how I will end up'.

A first observation can be made at this point. Respondents do admit that they see class differences in Dutch society, but they are not willing to construct a hierarchy and definitely not a hierarchy of personal worth. The equality ideal reverberates in people's discomfort with talking about class differences, particularly when they are asked to talk about those 'below' them. By defending their personal worth, choosing the middle position, apologizing to those below and ridiculing those above, they uncouple socioeconomic status from personal worth, thus flattening the hierarchy (cf. Lamont, 2000).

\section{Upgrading, Downgrading and the Construction of a Moral Hierarchy}

A second 'strategy' for uncoupling class and worthiness was to point to qualities other than socio-economic success that determined people's worth. When I asked Stefan whether he knows any people whom he would classify as lower class, he talks about friends and acquaintances he meets when going out:

I do still have a couple of friends who are unemployed and who've maintained that position for a very long time, so I would place them there [in the lower class]. [...] but to really talk about things that's not possible of course, anyway, not possible, but that's not to say they're stupid, mind, that they're not intelligent. Often they are, have a certain wisdom that I'd very much like to have, but different, so ... (41, consultant, academic education)

Cees described people in lower classes as people "who are fairly simple in their way of living and acting'. He enjoyed interacting with them 'because they are often very authentic of course' and 'more honest than others'. Here, authenticity is a moral quality (Mendez, 2008). For Wibbe, this was opposed to the artificial behaviour of the higher educated. This opposition served to simultaneously upgrade those at the socio-economic bottom and downgrade people at the top. In this way, respondents could redraw the boundaries based on moral qualities (cf. Lamont, 2000). Moral boundaries are centred around such qualities as honesty, work ethic, personal integrity, solidarity and consideration for others (Lamont, 1992). Here is what Wibbe says about low-class people (whom he imagines as 'hooligans') and higher-educated people: 
They're great people to interact with, on the job. Really simple, bold, tattoo in the neck with a barcode and on their back just really big 'I'm hooligan of Feyenoord' [a Dutch football club]. Great. [...] [They] have a small heart, but they're straightforward and easy to interact with. Because they're nice people. [...] Social interaction with the higher educated can be rubbish. And often with the normal, simple person, social interaction is either at once good or bad, they're anti-social or they're social. Whereas the higher educated can act social but are in essence almost a-social. (68, self-employed building inspector, low vocational training)

According to Wibbe, the higher educated are capable of pretending to be social and this makes them, in his eyes, non-social. Their dishonesty places them below the lowereducated people in the moral hierarchy. Mirjam also unlinked the connection between socio-economic status and respectable behaviour. She knows people who need rent subsidy so they are 'lower' than middle class. But:

They are not anti-social dumb people who are in all sorts of trouble and, no they're not, they don't have any debts, they always look decent, civilized speech, just, well, you know, well, no problems. (35, unemployed, housewife, secondary education)

Her neighbours, however, seemed to earn quite some money, but in terms of their behaviour Mirjam would say that they belong 'somewhere among the anti-socials', because they have repeatedly let their newly bought garden furniture rot away. Irresponsible behaviour can be a reason to deny those with more money and even the rich and famous their superior status. Cees, for example, would classify certain politicians as upper class, those who have 'a vision, a mission, a certain quality, they want to contribute something, so not purely for their career and for themselves'. In contrast, people who 'know a certain trick with which they can earn a ridiculous amount of money' - such as footballers and musicians - are not upper class, when they have 'too little to show for' in societal and political sense.

When it comes to morality, respondents make no apologies for judging those who hold 'wrong' moral standards - even when it comes to those with weaker socioeconomic positions. Hafida thus condemns the lower-class parents in her neighbourhood who let their 8-year-old children play outside till 9 or 10 o'clock in the evening. Jannie criticizes the moral standards of those 'foreigners' - echoing the oft-made connection between ethnicity and social problems - for 'they'll let their children play outside in the evenings, make more noise' and throwing litter on the streets.

What this suggests is that Dutch respondents are not hostile to expressing superiority and constructing a moral hierarchy per se: it depends on the type of boundary they draw. Apparently, constructing a hierarchy based on socio-economic status is unfair and not done, but when it comes to moral character respondents are clear about what is good and what is bad. Perhaps this is possible because they understand moral behaviour as an individual responsibility, unconnected to socio-economic status and class differences. Both lower and higher classes need to behave, and thus in judging certain behaviours and moral standards respondents feel that they hold everyone to the same standards: everyone is treated equally and the norm of mutual respect - between classes - is not violated. 


\section{Drawing Cultural Boundaries: Development, Taste and Individuality}

The interviews point to an additional way in which at least some respondents construct a moral hierarchy: by attaching moral value to education and self-development. Interestingly, only higher-educated respondents drew such boundaries. They were the only group who talked about education as an important factor in locating people in the class structure, and, more importantly, they were more likely to evaluate differences morally, thus coupling cultural boundaries with moral boundaries. For Madu (31, creative therapist, higher vocational training), upper-class people (like herself) are more developed in terms of reading books and the newspaper, watching the news and being aware of what is happening in the world. For Cees, it is about broadening one's interests:

Gwen: What kind of interests fit the middle [class]?

Cees: Well that you're not only watching The Golden Cage and broader political, cultural, societal sometimes financial interests. Instead of limiting yourself to the white picket fence life. (62, self-employed trader, academic training)

Here, mentioning a television program is not to illustrate bad taste but to make a negative judgement on limited personal development (cf. Lamont, 2000). Even people who did not study much can qualify as middle class when they are, in Ruth's words, 'developed, open to things, learning things, reading' (62, pensioned teacher, higher vocational training). Daniel sees the upper class as more developed in terms of 'literature, art, view on society', although someone who has 'broad knowledge' and is 'interested and open and mannered' also qualifies. As we saw earlier, Daniel dislikes classifying others, but overall it appears that respondents are less concerned with making qualifications and apologies when drawing cultural boundaries compared to drawing socio-economic boundaries. Hafida even stressed that she felt no need to apologize:

Hafida: My sister, she, no, she's the same as my sister-in-law. Yes I'm quite honest about this, no matter whether it's about my sister or my neighbour, that doesn't matter. $[\ldots]$

Gwen: So, a bit lower, lower middle?

Hafida: Yes. She finished primary school but she never did any work really. She's always stayed home for the children. And I find if you're a housewife then really you don't come outside that often. And if you work, then you're in touch more with people and you also hear other things and develop your knowledge. And then you start to grow I think.

Being educated does not make someone belong to the middle class, Hafida argues, for it involves a certain way of thinking and commitment to one's children, family, work and society. Perceiving class differences in this case had real consequences, as Hafida took her son to a different primary school because she 'did not fit in' with the other parents: 
There were parents who are just totally different. If we get together for example, I find it important that we see how our children are doing in school, the quality of education that sort of thing. Well there you are talking about the quality of education, they don't know what you're talking about. (36, nurse, higher vocational training)

More often than for socio-economic difference, respondents describe whether or not one is developed not just as a difference but as a valuable personal quality: developing yourself is what one should do. Thus, higher-educated respondents, by drawing cultural boundaries, were more inclined to construct a moral hierarchy related to class position. However, by evaluating self-development as a personal quality, they individualized class position. This contrasts with the way in which respondents understood socio-economic differences: socio-economic status was not explicitly referred to as a personal achievement and was not individualized. Individualizing class position seems conducive to the hierarchalization of differences, whereas class position understood in terms of socio-economic differences is not. The emphasis on education and self-development as personal qualities corresponds with a utilitarian form of individualism, which focuses on accomplishment, achievement, personal unfolding and responsibility for one's acts (Bellah et al., 2007). This mode of individualism is 'hard' and 'rational' and particularly appropriate in economic and occupational life. This particular view of individuality is central to the current neoliberal politics that is dominant in many western societies, the Dutch included. In a sense, that highereducated respondents attach moral evaluations to one's educational achievement echoes the neoliberal demand that people take responsibility for their lives and their achievements in society.

This 'hard' individualism contrasts with a more 'soft' notion of individuality that emphasizes the enjoyment of life, uniqueness, creativity and freedom. Bellah et al. (2007) refer to this mode as expressive individualism, which is based on feelings rather than rationality, and appropriate in private life. When respondents referred to difference based on taste - and again, only higher-educated respondents drew such cultural boundaries - they articulate this soft notion of individuality. As we saw, respondents made no apologetic or mitigating qualifications when drawing cultural boundaries in terms of education and development. When talking about differences in taste, they did make qualifications, making sure not to evaluate the consumption choices and preferences of others. Taste, according to Bourdieu, is foremost the 'refusal of other tastes' and in this way 'perhaps one of the strongest barriers between the classes' (1984: 56). However, the respondents seemed careful not to imply that different tastes are 'bad tastes'; rather, respondents felt compelled to explicate their tolerance towards different tastes, by adding that they were just different. Thus, class in terms of taste was also individualized, but now to the effect of negating class hierarchy. To give an example, for Vivien, who self-classifies as middle class, people in the lower class are different for instance because they always wear make up. When I ask whether she knows any lower-class people, she mentions a colleague. After stressing twice that they have a really strong bond, Vivien explains that the lowerclass position of her colleague shows because she always wears make up and dresses differently: 
More posh, more open here [points to cleavage], not really sporty, you know, a skirt, always elegant [...] But too much, a bit too [elegant]. Frankly it's not my taste, I'm more sporty, practical, I cycle everywhere, I can't wear a skirt. (51, GP, academic education)

Vivien thus sees class differences reflected in how people present themselves, but downplays the difference as a matter of individual taste and thus avoids having to construct a hierarchy of worthiness. Liesbeth thinks that class is also about lifestyle, whether one spends money on 'a good book' or eating out:

Gwen: And does it matter what kind of books you read or what kind of movies you watch?

Liesbeth: Yes I believe so. It doesn't matter for me, I think it's fine if they watch something else. Some films at the art house are more fun than at the Pathé [mainstream cinema]. But that doesn't mean I would never go to the Pathé. And if we're talking about music, I would never go to Frans Bauer [Dutch folk singer] and maybe would to the Rotterdam Philharmonic orchestra. And if we're talking about class, than I think that it is more likely you found someone of a higher class at the Rotterdam Philharmonic than at Frans Bauer.

Like Vivien, Liesbeth admits that there is a connection between class and taste, but refuses to make claims about superior and inferior tastes, thus restraining from constructing a class hierarchy.

For higher-educated respondents, drawing cultural boundaries thus involves two different modes of individualism: a 'hard' view on individuality that emphasizes people's moral responsibility for achievement and self-development, and a 'soft' view on individuality that focuses on creativity and freedom. It is this latter, expressive mode that dominated in the Netherlands of the 1970s when calls for emancipation and individual freedom were strongest (Bussemaker, 1993) and that now reverberates in class talk as the equality ideal, flattening class hierarchy. However, in the 1980s, the utilitarian mode came to dominate political views (Bussemaker, 1993 ) and with the rise of neoliberal politics this mode has become even more dominant, which has manifested itself in state withdrawal and deliberate policies to increase income differences in order to stimulate economic growth and employment opportunities (De Beer, 1999). It is this 'hard' mode of individualism that is invoked when higher-educated respondents talk about the value of education, development and 'broad interests' and the moral responsibility to educate oneself. Thus, only in relation to the 'hard' notion of individuality are cultural boundaries equated to moral boundaries. Respondents are then more inclined to construct a moral hierarchy. They make no apologetic qualifications, and may think it is not necessary as they are not violating the taboo on expressing superiority, as, in the respondents' view, development is not class based but an individual responsibility. Nonetheless, although one form of cultural boundary-making is conducive to hierarchalization (education) and the other (taste) is not, both ways in which class differences are individualized help deny and ignore the classed nature of differences in cultural resources and cultural consumption. 


\section{Conclusion}

This study demonstrates how a cultural class analysis is relevant for Dutch society and sociology, in explicating boundary work and (dis)identification in relation to perceived class differences. Considering the common-sense view that class no longer matters in Dutch society, it is noticeable that the 27 Dutch respondents talked about class in such a detailed and personalized way. Indeed, they were not asked to talk about class 'out there' but about their perceptions of class differences in personal relationships. Sometimes they talked about general social categories - the economic elite, politicians, foreigners, poor people - but most did not shun talking about how class matters in their personal social life, however uncomfortable they felt. In this respect, they differ from the respondents in Savage et al.'s study, who 'seem keen to invoke a distinction between their personal lives - in which class is rarely seen as a salient issue - and the world "out there", the world of politics, the economy, the media and so forth' (2001: 117). Perhaps this discrepancy is the result of the different questions that were asked, which would support Payne and Grew's (2005) argument that the way in which the researcher approaches 'class' shapes the answers one gets. In any case it shows how class differences are actually experienced by people in everyday life in Dutch society. If people were truly convinced that class is insignificant, we would expect more people to refuse to talk about class. That respondents proved willing and able to talk, and think out loud, about class differences, supports the argument that class identity is a latent identity (De Regt and Weenink, 2003) which is activated in particular situations and particular real, imagined or mediated interactions (e.g. with the economic elite, politicians, deprived groups). Moreover, class identity is a carefully concealed identity, hidden, perhaps unintentionally, by notions of individuality, and denied, perhaps more deliberately, in relation to notions of equality of personal worthiness.

Cultural repertoires about individuality and equality thus play a role in justifying or concealing the practice of boundary making, and hierarchalization of differences in particular. In this way, the study contributes to cultural class analyses in a broader context by disentangling the hidden and morally problematic nature of class and the resulting ambivalence of people towards class, as described by Savage, Sayer and others. Notions of equality and individual autonomy undermine and threaten the idea that class still matters. However, as this study has shown, in order to deny the role of class these ideals are not necessarily invoked explicitly. They may also work indirectly by individualizing educational, moral or cultural with the effect of justifying the construction of a moral hierarchy and hiding its class base. The higher-educated Dutch respondents thus constructed a class hierarchy based on cultural resources. To the extent that claims to, and expressions of, individuality function as symbolic capital (Savage, 2000), this strategy underpins the view that class is powerful because it is hidden. Understanding the connection between individualism and class is particularly relevant in the context of current neoliberal policies which emphasize and, more importantly, demand individual responsibility, while ignoring structural causes of inequality in resources and recognitions. Further research could shed more light on how neoliberalism as a cultural repertoire shapes perceptions of class differences, while simultaneously justifying moral evaluations of achievements and concealing the classed nature in practices of distinction through socio-economic success, educational achievement and cultural consumption. 


\section{Acknowledgements}

I thank Mike Savage and two anonymous reviewers for their insightful comments on earlier drafts.

\section{Funding}

The interviews were carried out as part of a larger research project financed by OTB Research Institute for the Built Environment, Delft University of Technology. A personal scholarship from the Niels Stensen Foundation enabled me to write this article.

\section{References}

Atkinson W (2007) Beck, individualization and the death of class: A critique. British Journal of Sociology 58(3): 349-66.

Beck U (1992) Risk Society. London: Sage.

Bellah RA, Madsen R and Sullivan WM (2007) Habits of the Heart. Berkeley: University of California Press.

Bennett T, Savage M, Silva E, Warde A, Gayo-Cal M and Wright D (2009) Culture, Class, Distinction. London: Routledge.

Bottero W (2004) Class identities and the identity of class. Sociology 38(5): 985-1003.

Bourdieu P (1984) Distinction. Cambridge, MA: Harvard University Press.

Bussemaker J (1993) Betwiste zelfstandigheid: individualisering, sekse en verzorgingsstaat [Contested autonomy: individualization, gender and welfare state]. Amsterdam: SUA.

Cannadine D (1998) Class in Britain. London: Penguin.

Day G (2001) Class. London: Routledge.

De Beer P (1999) Misvattingen en taboes van het inkomensbeleid [Misconceptions and taboos of income policies]. In: Becker F, Van Hennekeler W and Tromp B (eds) Hedendaags kapitalisme [Contemporary capitalism]. Amsterdam: De Arbeiderspers/Wiardi Beckman Stichting, 144-80.

De Regt A and Weenink D (2003) Investeren in je kinderen. Over de keuze voor particular onderwijs in Nederland [Investing in your children. On choosing private schooling in the Netherlands]. Amsterdam: Boom.

De Swaan A (1997) Uitgaansbeperking en uitgaansangst; over de verschuiving van bevelshuishouding naar onderhandelingshuishouding [Restriction and fear of going out; on the shift of an order household to a negotiation household]. In: De Swaan A De mens is de mens een zorg. Opstellen 1971-1981. Amsterdam: Meulenhoff, 81-115.

Duyvendak JW, Hendriks F and Van Niekerk M (eds) (2009) City in Sight. Amsterdam: Amsterdam University Press.

Engbersen G (2005) Een eeuwige jeugd. Constanten en vernieuwingen binnen de Nederlandse sociologie [An eternal youth. Constants and innovations in Dutch sociology]. Sociologie 1(1): 90-105.

Evans MDR, Kelley J and Kolosi T (1992) Images of class: Public perceptions in Hungary and Australia. American Sociological Review 57(4): 461-82.

Goudsblom J (1967) Dutch Society. New York: Random House.

KNAW (2006) Samenleven en samenwerken. Een toekomst voor de Nederlandse sociologie [Living and working together. A future for Dutch sociology]. Amsterdam: Koninklijke Nederlandse Akademie van Wetenschappen.

Kuipers G (2006) Good Humor, Bad Taste. A Sociology of the Joke. Berlin: Mouton de Gruyter. Lamont M (1992) Money, Morals, and Manners. Chicago, IL: University of Chicago Press. Lamont M (2000) The Dignity of Working Men. Cambridge, MA: Harvard University Press. Lawler S (2005) Introduction: Class, culture and identity. Sociology 39(5): 797-806. 
Lijphart A (1975) The Politics of Accommodation, 2nd rev. edn. Berkeley: University of California Press.

Méndez ML (2008) Middle class identities in a neoliberal age: Tensions between contested authenticities. Sociological Review 56(2): 220-37.

Minister of Education (2012) Letter to the House of Representatives, 16 January. Available at: http://www.adviesorgaan-rmo.nl/files/file.php5?id=331 (accessed 21 February 2012).

Pahl R, Rose D and Spencer L (2007) Inequality and Quiescence: A Continuing Conundrum. ISER Working Paper 2007-22. Colchester: University of Essex.

Payne G and Grew C (2005) Unpacking 'class ambivalence': Some conceptual and methodological issues in accessing class cultures. Sociology 39(5): 893-910.

Reay D (1997) Feminist theory, habitus, and social class: Disrupting notions of classlessness. Women's Studies International Forum 20(2): 225-33.

Reay D (2005) Beyond consciousness? The psychic landscape of social class. Sociology 39(5): 911-28.

RMO (2011) Nieuwe ronde, nieuwe kansen. Sociale stijging en daling in perspectief [New round, new opportunities. Upward and downward social mobility in perspective]. Den Haag: Raad voor Maatschappelijke Ontwikkeling.

Sassen S (2001) The Global City. Princeton, NJ: Princeton University Press.

Savage M (2000) Class Analysis and Social Transformation. Buckingham: Open University Press.

Savage M, Bagnall G and Longhurst B (2001) Ordinary, ambivalent and defensive: Class identities in the northwest of England. Sociology 35(4): 875-92.

Savage M, Bagnall G and Longhurst B (2005) Globalization and Belonging. London: Sage.

Sayer A (2005) The Moral Significance of Class. Cambridge: Cambridge University Press.

Van den Brink G (2004) Schets van een beschavingsoffensief [Outline of a civilization offensive]. Amsterdam: Amsterdam University Press.

Van Eijk G (2010) Unequal Networks. Spatial Segregation, Relationships and Inequality in the City. Amsterdam: IOS Press.

Van Elteren M (1998) The riddles of individualism and community in American and Dutch society. Journal of American Culture 21(1): 43-80.

Weenink D (2005) Sociale klasse: de eeuwige jeugd van een 'zombiecategorie' [Social class: The eternal youth of a 'zombie category']. Sociologie 1(3): 316-24.

Wouters C (1990) Van minnen en sterven. Informalisering van omgangsvormen rond seks en dood [Of loving and dying. Informalization of manners concerning sex and death]. Available at: http://www.dbnl.org/tekst/wout020minn01_01/ (accessed 21 February 2012).

Wouters C (2011) Informalization. In: Southerton D Encyclopedia of Consumer Culture. Thousand Oaks, CA: Sage, 1-4.

Zeldenrijk D (2010) Je voelt het gewoon. Een onderzoek naar schoolkeuze en segregatie in Amsterdam-Noord [You just feel it. A study on school choice and segregation in Amsterdam North]. Den Haag: Raad voor Maatschappelijke Ontwikkeling.

Gwen van Eijk is Assistant Professor of Criminology at the Institute for Criminal Law and Criminology and Research Fellow of the Meijers Research Institute and Graduate School, both at Leiden University in the Netherlands.

Date submitted August 2011

Date accepted April 2012 